Supplement of Atmos. Chem. Phys. Discuss., 15, 10299-10340, 2015

http://www.atmos-chem-phys-discuss.net/15/10299/2015/

doi:10.5194/acpd-15-10299-2015-supplement

(C) Author(s) 2015. CC Attribution 3.0 License.

(c) (1)

Supplement of

\title{
Effects of urban land expansion on the regional meteorology and air quality of Eastern China
}

W. Tao et al.

Correspondence to: J. Liu (jfliu@pku.edu.cn) 


\section{S1 Urban land expansion scenarios}

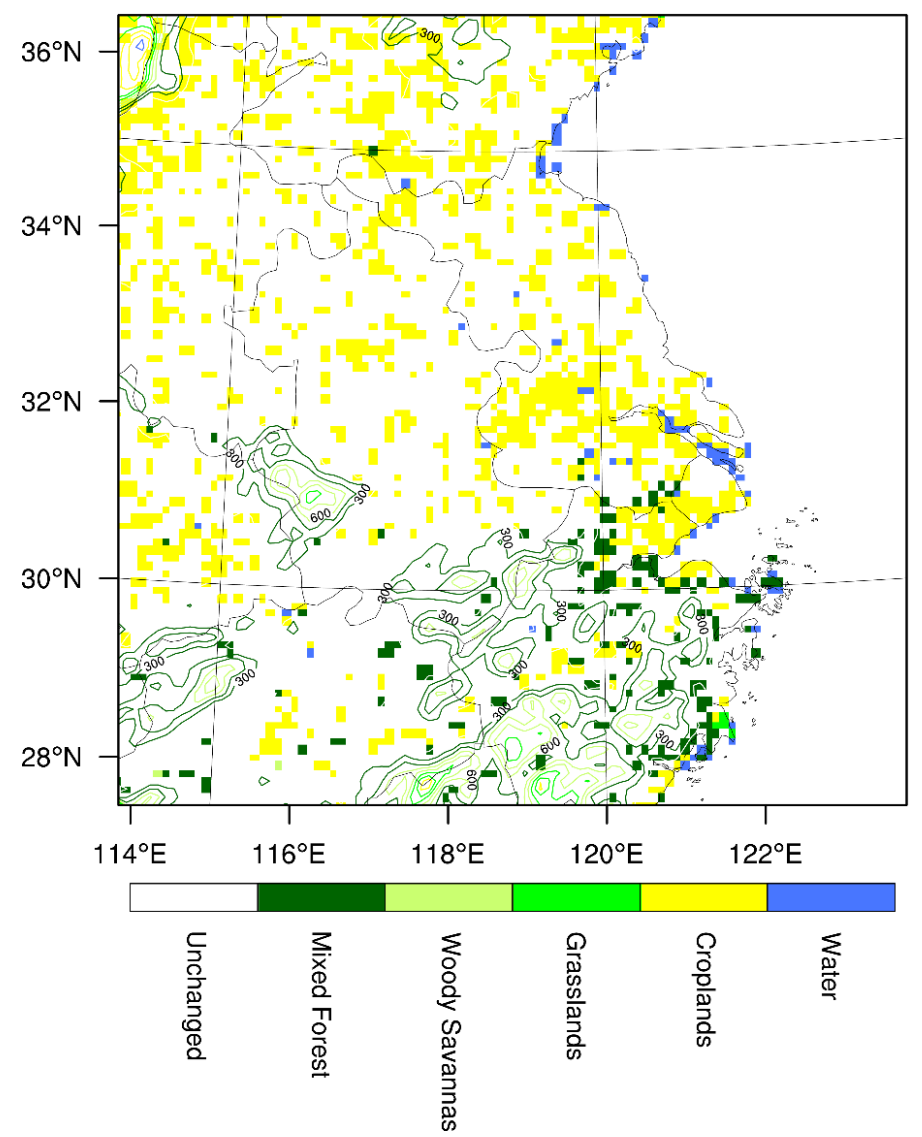

Figure S1: The original main land use categories of newly urbanized grids in GT0 run and contour map for the terrain height (meters) in the domain of interest. 


\section{S2 Verification of IPR}

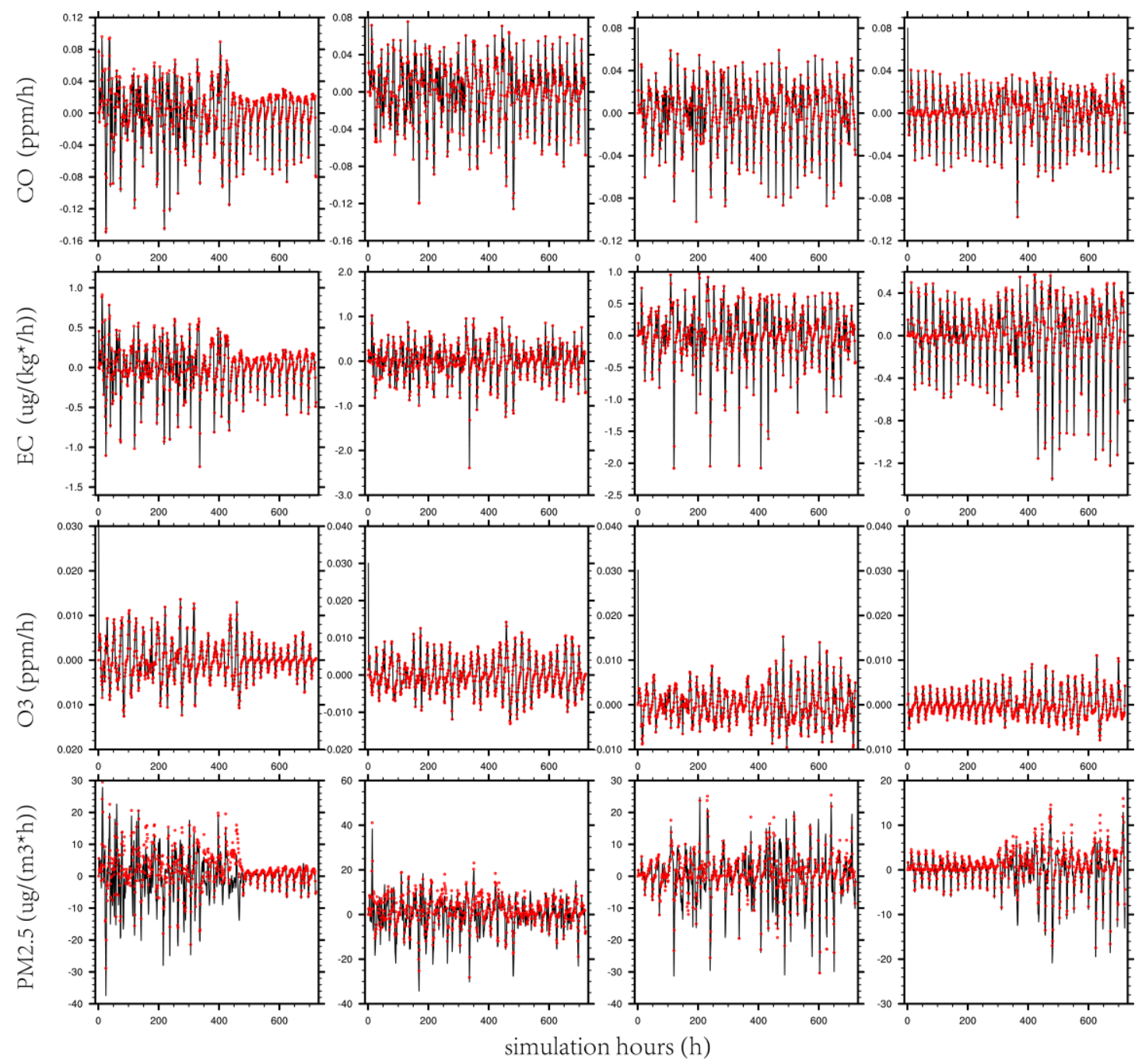

Figure S2: Hourly concentration change (black solid line) and the sum of hourly IPR of ten processes (red dot) averaged over four random 10km×100km subregions during July of 2012.

\section{S3 Sensitivity of meteorological fields to land use changes}

Fig. S3 shows the 5-year averaged July mean of 10-meter wind speed (W10), boundary layer height (PBLH), hourly precipitation (PREC), 2-meter temperature (T2) and 2-meter relative humidity (RH2) in BASE run and the three sensitivity tests. It illustrates that the expansion of urban land could significantly modify 5-year July mean values of local W10, PBLH, T2 and RH2 to different extents (one-tailed t-tests with the significance level of $95 \%$ were utilized). To begin with, terrestrial W10 (less than $4 \mathrm{~m} \cdot \mathrm{s}^{-1}$ ) was typically weaker than the marine W10 by $1-3 \mathrm{~m} \cdot \mathrm{s}^{-1}$, probably due to 
difference in roughness length of underlying surfaces. The replacement of crop land (mixed forest) by urban land could significantly reduce (increase) W10.

In Fig. S3, higher values of PBLH $(600-800 \mathrm{~m})$ and T2 $\left(\sim 30^{\circ} \mathrm{C}\right)$ as well as lower values of RH2 (60\%-70\%) were found in urban areas. Terrestrial precipitation mostly ranged from $0.3 \mathrm{~mm}$ to $0.9 \mathrm{~mm}$ per hour. It can be also found that a relative higher PBLH and lower RH2 zone appeared in northern terrestrial domain. Urban land expansion could significantly increase PBLH (max. 64\%; avg. 24\%, 130m in the GT0 run), surface temperature (max. $11 \%$; avg. $6 \%, \sim 1.6^{\circ} \mathrm{C}$ in the GT0 run) and reduce $\mathrm{RH}$ ( $\max .70 \%$; avg. $15 \%, \sim 11 \%$ in the GT0 run). Note that one-tailed t-tests were also performed for each year, and the effect of urban land expansion on W10, PBLH, T2 and RH2 was simulated to be consistent for each year but with slightly different magnitudes. Other relevant mesoscale modeling studies reported similar results, and such phenomena could be explained by the parameterization of urban land's unique physical properties with a higher albedo and roughness length, a greater thermal capacity and conductivity, as well as lower intensities of evaporation and transpiration. It can also be found that, besides the local effects, the forcing of urban land expansion can affect the W10, PBLH, T2 and RH2 of nearby non-urbanized areas, but the BASE magnitude is much weaker. Given a certain large-scale synoptic background, the magnitude of urban land climatic perturbation did not respond linearly to urban land fraction, this will be discussed later.

As for July mean PREC, unlike other meteorological variables, the results of one-tailed t-tests did not show consistency from year to year, the PREC in many newly urbanized grids was significantly enhanced in some years while hindered in other years. When averaging the PREC over 5 years, PREC was only significantly intensified in some newly urbanized areas over the central domain. Previous studies have demonstrated diverse results. Factors potentially leading to more PREC include updraft induced by urban heat island circulation convergence (Wang et al., 2012), increment of condensation nuclei due to emissions of airborne pollutants, and drag of 
precipitation system by urban buildings. Conversely, factors hindering PREC include reduction in water vapor ratio (“dry island" effects) (Kaufmann et al., 2007) and the perturbed cloud microphysics processes by smoke with small CCN (Rosenfeld, 2000). Zhang et al. (2010) declared that precipitation tended to decreased about $15 \%$ over urban or leeward areas in summer but changed slightly in winter in Yangtze River Delta of China if urban land were replaced by crop land. But as reported in a WRF/UCM simulation, with increasing urban land fraction, the rainfall was increased in Beijing-Tianjin-Hebei metropolitan area while decreased in Pearl River Delta and Yangtze River Delta (Wang et al., 2012), such results are exactly the opposite of the 50-year observation results ( $\mathrm{Li}, 2013)$, maybe due to that the long-term evolution of regional precipitation is subject to circulation changes of larger spatial and temporal scales. The issues of how urbanization would impact the precipitation remain uncertain. Nonetheless, the modeling results in Sect. 6 show that precipitation played a trivial role in forcing the spatial distribution of airborne pollutants on the time scale of a month. 
BASE
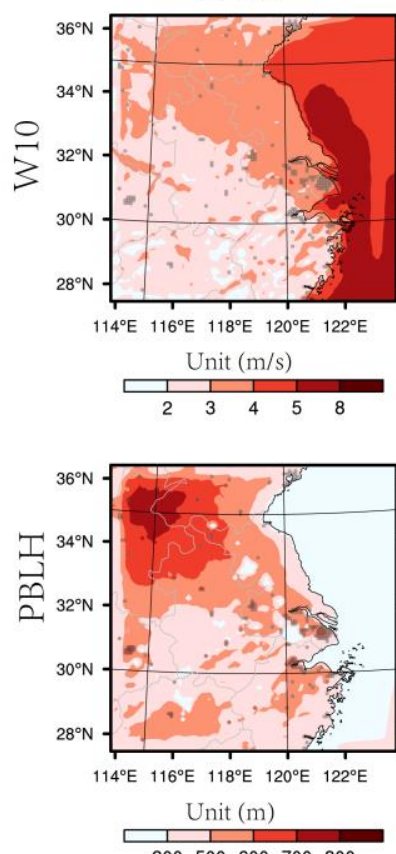

$\frac{1}{300500600700800}$
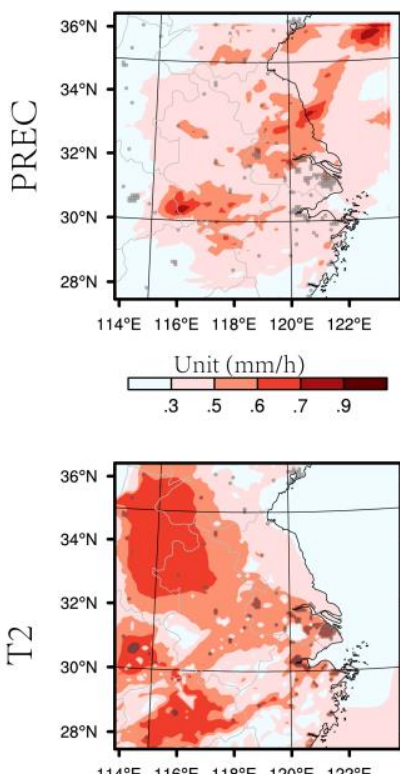

$114^{\circ} \mathrm{E} \quad 116^{\circ} \mathrm{E} \quad 118^{\circ} \mathrm{E} \quad 120^{\circ} \mathrm{E} \quad 122^{\circ} \mathrm{E}$
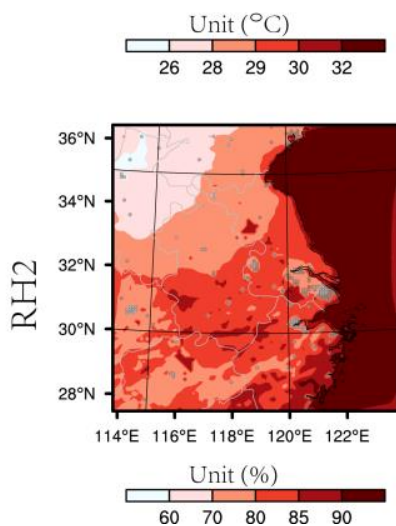

GE0.2
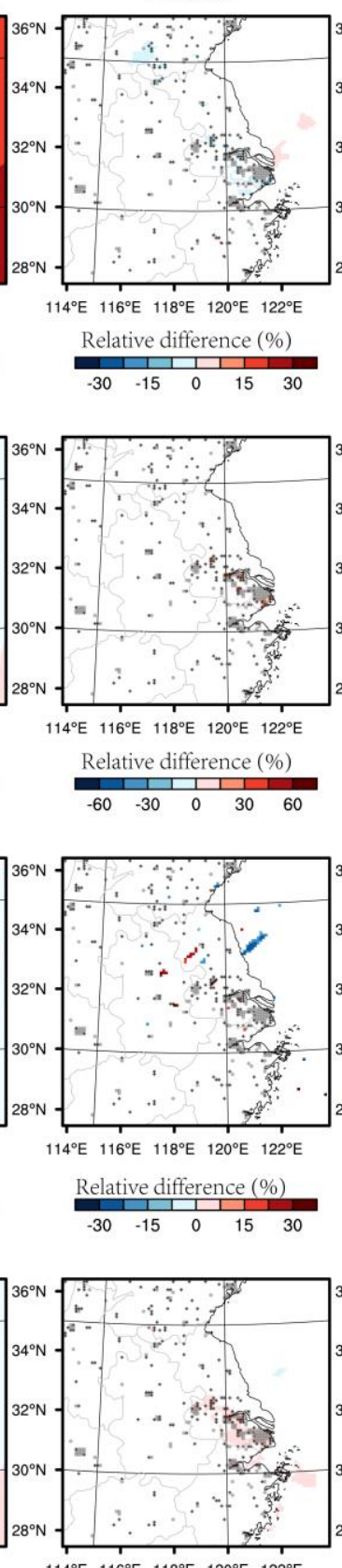

$114^{\circ} \mathrm{E} \quad 116^{\circ} \mathrm{E} \quad 118^{\circ} \mathrm{E} 120^{\circ} \mathrm{E} \quad 122^{\circ} \mathrm{E}$
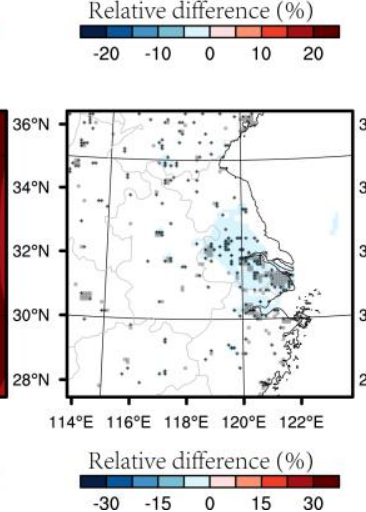

GE0.1
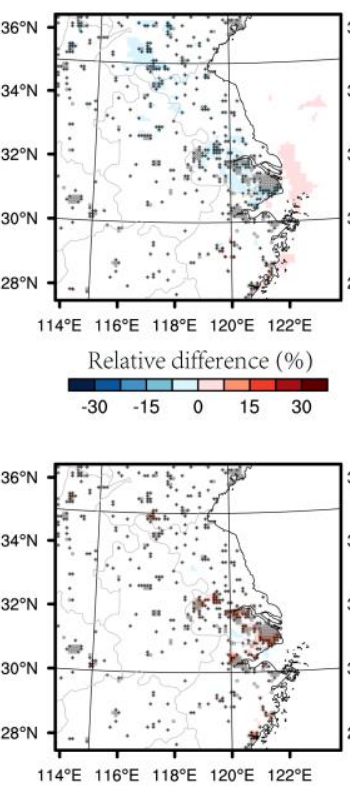

Relative difference (\%)
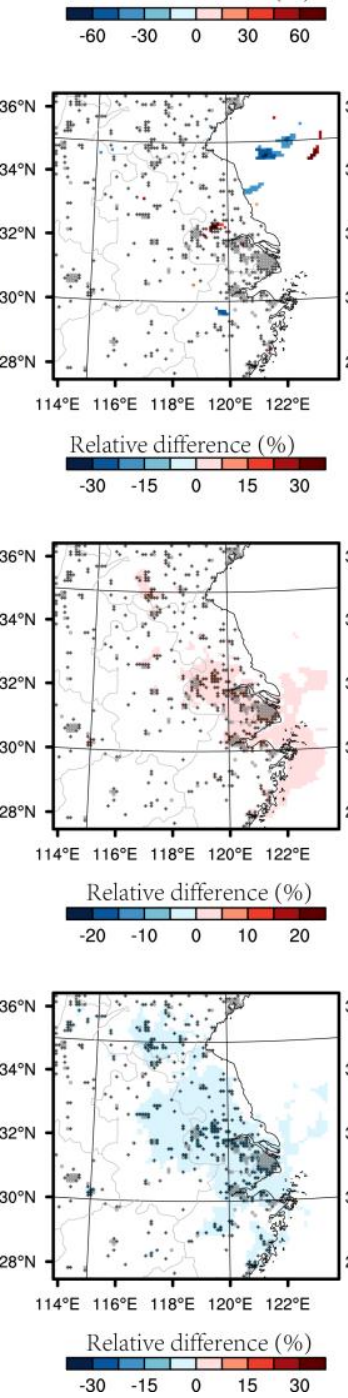

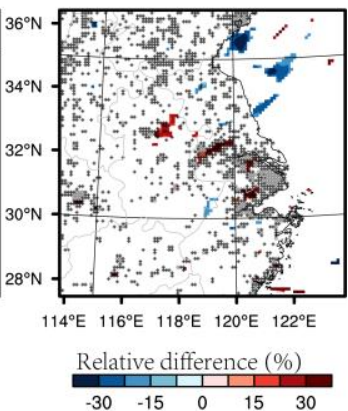

GT0
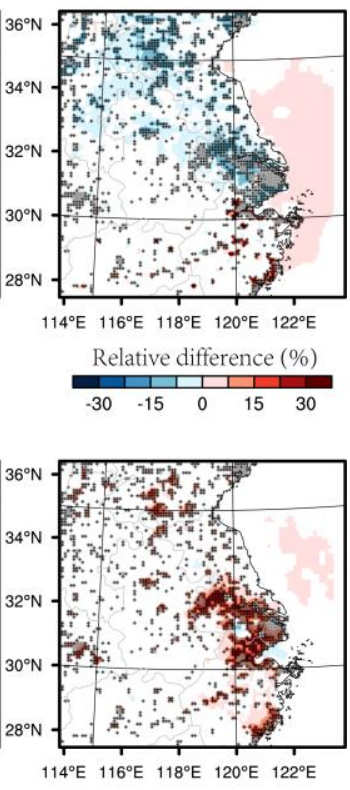

Relative difference (\%)

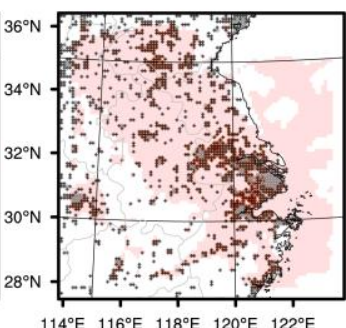

Relative difference (\%)
\begin{tabular}{llllll}
\hline & 1 & 1 & 1 & 1 & \\
\hline-20 & -10 & 0 & 10 & 20
\end{tabular}

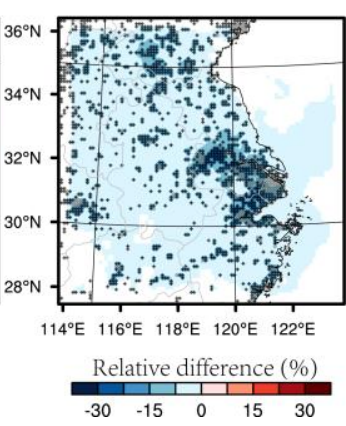

Figure S3: Averaged levels (July from 2008 to 2012) of 10-meter wind speed (W10), boundary layer height (PBLH), hourly precipitation (PREC), 2-meter temperature (T2) as well as 2-meter 
relative humidity (RH2) of BASE run, and the relative difference (one-tailed t-tests with the significance level of $95 \%$ were utilized, only the significant changes were drawn) between each sensitivity run and BASE run. Circle markers indicate the locations of urban areas in the BASE run, while cross markers indicate the locations of newly urbanized areas in 3 urban land expansion scenarios of GE0.2 run, GE0.1 run and GT0 run.

\section{S4 The synergistic effect of urban land forcing on meteorological factors}

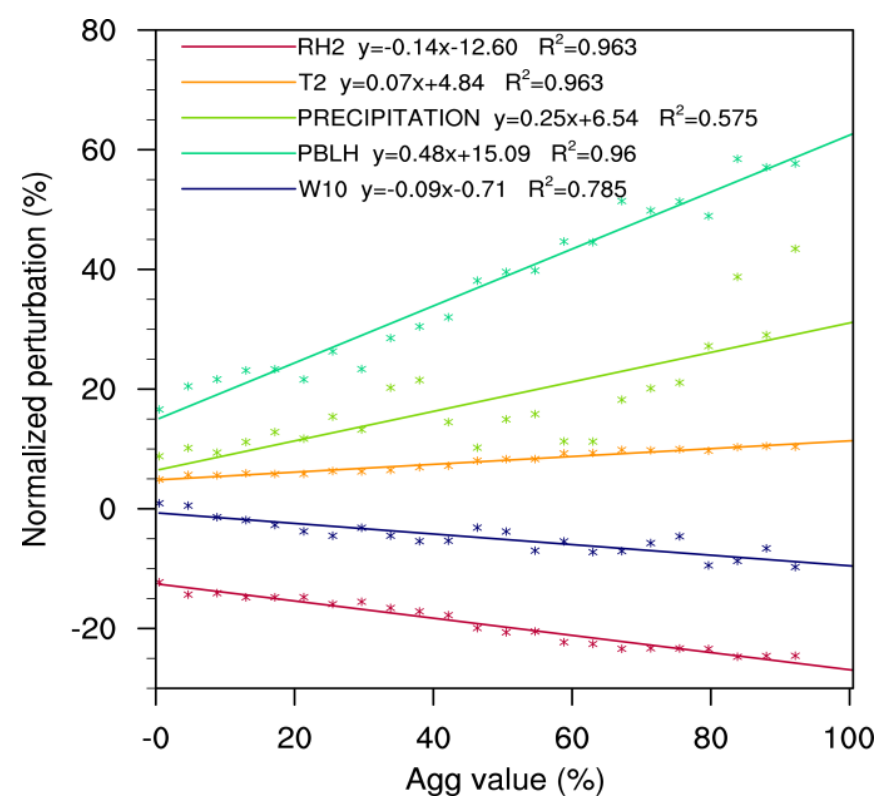

Figure S4: The linear regression of 5-year July mean level perturbations of 2-meter temperature (T2), boundary layer height (PBLH), 2-meter relative humidity (RH2), hourly precipitation (PREC) and 10-meter wind speed (W10) to Agg value. 
S5 The IPR diurnal cycle of $\mathrm{O}_{3}$ of northern and southern LOCAL

grids
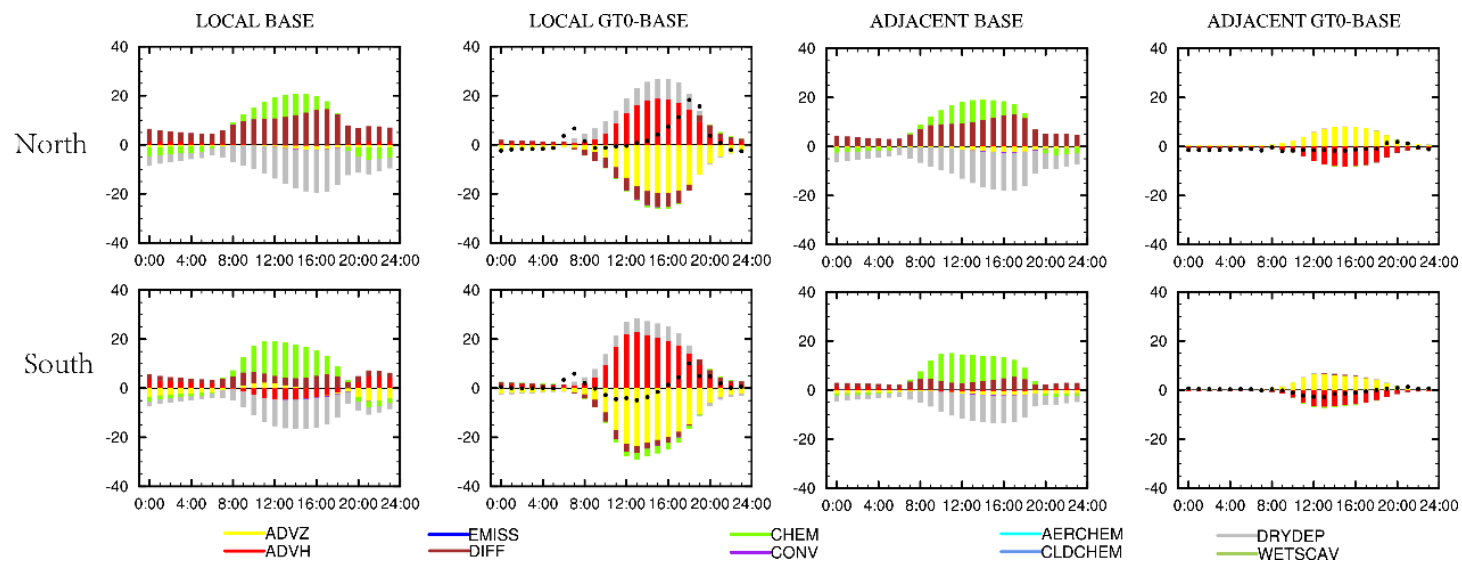

Figure S5: 5-year July mean diurnal cycle of O3 IPR bar of BASE run and its difference with GT0 run in the surface layer averaged over northern and southern (reference latitude was $30^{\circ} \mathrm{N}$ ) LOCAL as well as ADJACENT grids.

\section{S6 The IPR vertical profile in ADJACENT grids}

The UHIC induced advection changes were exactly the opposite from those in LOCAL grids.
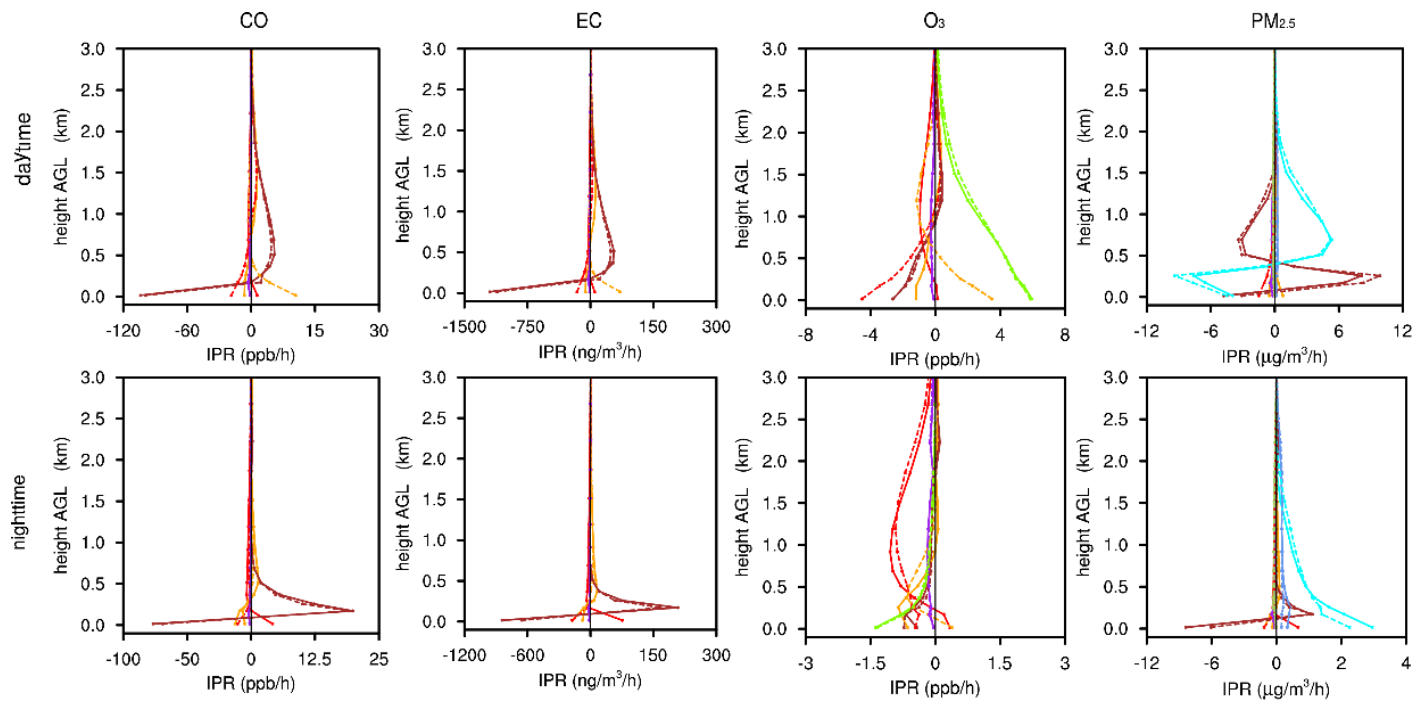

BASE ADVZ
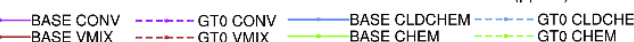
BASE WETSCAV
BASE AERCHEM - GTO WETSCAV

Figure S6: 5-year July mean IPR vertical profile averaged in domain-wide ADJACENT grids. 


\section{S7 The isoperene vertical profile}

Due to increased surface temperature caused by urban land expansion, the biogenic emission of VOCs increased, e.g. the isoprene emission experienced a $6 \%$ increment. However, the higher emission rate did not compensate the enhanced sink due to vertical transport.

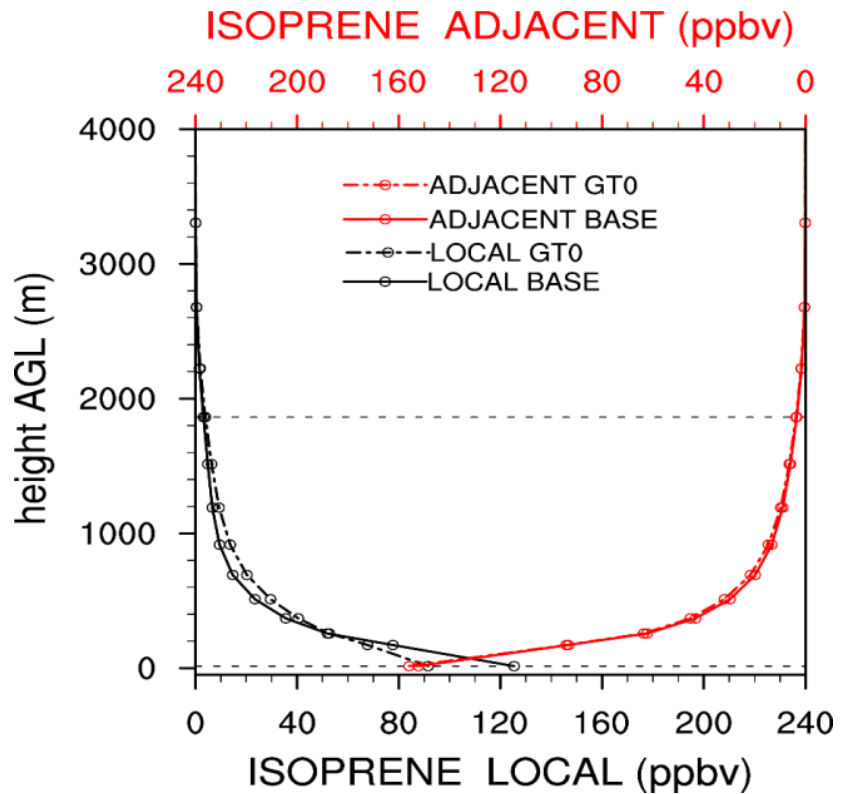

Figure S7: 5-year July mean vertical profile of isoprene in LOCAL and ADJACENT grids.

\section{Reference}

Kaufmann, R. K., Seto, K. C., Schneider, A., Liu, Z., Zhou, L., and Wang, W.: Climate response to rapid urban growth: Evidence of a human-induced precipitation deficit, Journal of Climate, 20, 2007.

$\mathrm{Li}, \mathrm{Y}$.: Impacts of urbanization in different regions of eastern China on precipitaiton and its simulation (in Chinese), Master thesis, Department of atmospheric sciences Nanjing, Nanjing University of Information Sciences \& Technology, 2013.

Rosenfeld, D.: Suppression of rain and snow by urban and industrial air pollution, Science, 287, 1793-1796, 2000.

Wang, J., Feng, J., Yan, Z., Hu, Y., and Jia, G.: Nested high - resolution modeling of the impact of urbanization on regional climate in three vast urban agglomerations in China, Journal of Geophysical Research: Atmospheres 117, 10.1029/2012JD018226, 2012.

Zhang, N., Gao, Z. Q., Wang, X. M., and Chen, Y.: Modeling the impact of urbanization on the local and regional climate in Yangtze River Delta, China, Theoretical and Applied Climatology, 102, 331-342, 10.1007/s00704-010-0263-1, 2010. 